\title{
INDIVIDUAL VARIATION IN THE SIZE OF THE TENTORIAL OPENING
}

\author{
BY \\ J. A. N. CORSELLIS \\ From Runwell Hospital, Wickford, Essex, and the Department of Neuropathology, Institute of Psychiatry, \\ Maudsley Hospital, London
}

Pathological study of transtentorial herniation in man is made difficult by the fact that manipulation of the unfixed brain within the skull quickly leads to distortion. Moreover, when the brain is removed in the conventional way by approaching it from above, both its blood vessels and the dural sheath are eventually cut through at the very level that ought ideally to be preserved.

If it were practicable, therefore, a more revealing approach might well be that directed through the base of the skull, the brain having been fixed in situ. In this way the tent would be completely exposed from below and its relation to the brain-stem and surrounding structures could be more precisely examined since they would remain intact.

In order to do this, however, a simple technique is needed which would not only make it possible to obtain such a specimen during a routine post-mortem examination but would also allow for complete and immediate artificial reconstruction of the head.

Remarkably enough, although Martin (1952) and Small and Woolf (1957) both refer to the removal of the skull in special cases, no such technique for general use appears to be described, and it is for this reason that the present method is reported.

It has been carried out so far in 21 cases, which were collected at random but mostly from mental hospital patients in order to illustrate the anatomical relationships of the temporal lobes and their blood supply to the brain-stem and the tentorial edge.

In the course of this study, an unexpected finding has been the marked variation from case to case in the size of the tentorial opening. This has been sufficiently striking to suggest that it might play a material part in the particular way that a given brain tends to herniate.

The present report therefore describes first a post-mortem technique for the study of the tentorium from below, and secondly the individual variation in the size and shape of the tentorial opening that has been revealed by the use of this method.

\section{Post-mortem Technique}

The soft tissues in the mouth and neck are removed in the usual way from below through a U-shaped incision, the arms of which, however, are continued up behind the ears to meet over the vertex. The two skin flaps are dissected off the skull. The anterior one is carried forward to the brows and, after a deep cut (on both sides) through the external auditory meatus, continued down past the lateral edge of the orbit as far as the angle of the jaw. The posterior flap is reflected back to high cervical level. A horizontal saw-cut is started anteriorly as if the whole skull cap were to be removed but it is carried back on both sides only as far as the coronal suture. A long, thin knife is passed between the temporal muscle and the zygomatic arch, and allowed to make its own way deep to the mandible into the neck. The line of the blade as it lies in the crook of the frontal process of the zygomatic bone is marked on the skull. The knife is withdrawn and the manoeuvre repeated on the other side. A coronal saw cut is then completed across the vault and along the line made by joining up these two marks. This cut will cross the ends of the horizontal one made earlier and so release a crescent of frontal bone which can be lifted out to reveal the dura overlying the pre-frontal areas. The membrane is snipped through and a "pre-frontal lobectomy" is completed by slicing off the exposed brain. The plane of this cut is a coronal one and usually passes just rostral to the tip of the anterior horns of the lateral ventricles.

A keyhole saw with a blade about 10 in. long is now passed on either side along the track left by the long knife, again ensuring both that the blade lies deep to the ramus of the mandible and that the point is clear of the skin flap in the neck. A saw cut is made coronally across the skull to the mid-line, and this is joined by a similar one which is made from the opposite side. The saw is withdrawn and once more inserted on each side in turn but with the teeth pointing posterolaterally in order to sever the temporo-mandibular joints. Any remaining soft tissue is cut through, and the face mask is lifted away.

The plane of the coronal saw cut lies at the back of the orbits but in front of the tip of the middle fossa so that the brain caudal to this remains intact.

Finally, a transverse saw cut is made through the vertebral column just below the foramen magnum. The skull block is now free (Fig. 1). 


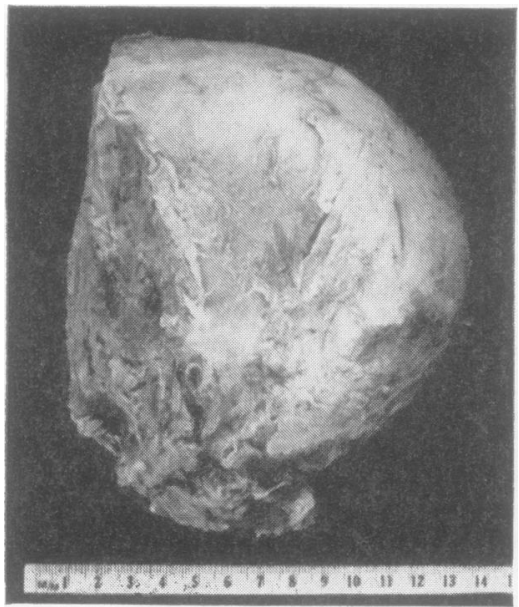

Fig. 1

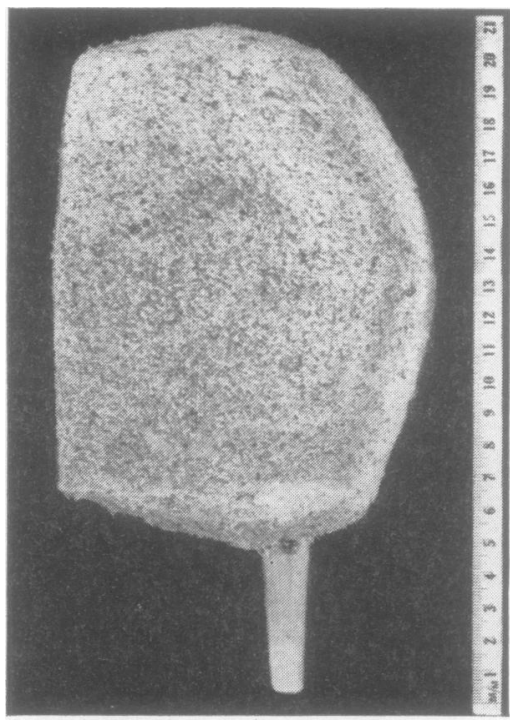

Fig. 1.-Lateral view of the skull block after its removal from the body. $\times \frac{1}{8}$

Fig. 2.-Lateral view of the cast used for replacement.
The head is immediately reconstructed by the insertion of a cast, kept in stock in two sizes, and pre-fabricated as follows. A wooden mould made in two halves is hollowed out to the required shape (that of Fig. 2). Its walls are greased with soft soap and it is packed with a mixture by weight of sawdust 4 parts, commercial plaster of Paris 6 parts, and water. This is a convenient mixture to use for casting since after a few hours' setting it is light and can be worked easily with a saw. A tapered wooden peg, which is destined to slide into the exposed vertebral canal, is embedded in the base at the time of mixing (Fig. 2). For use, the cast is slipped into position and the face mask laid on its flat surface. If necessary the edges of the cast are shaped with a saw to fit between the rami of the mandible. The crescent of frontal bone is replaced over a small pad of tow and the skin sewn up in the usual way.

With a little practice, this is a quick, simple and reliable technique, lengthening the post-mortem examination by about a quarter of an hour. The only extra instrument required is a carpenter's keyhole saw handle and a small stock of blades. An electrically-driven Desoutter necropsy saw, however, is an invaluable aid, especially for the further opening of the skull after fixation.

Fixation.-Before immersing in $10 \%$ formol saline, the anterior horns of the ventricles were opened. In the present series the fixing fluid was changed after one day, three days, and one week, and fixation was usually helped by partially opening the base and/or the skull cap either during the post-mortem examination or a few days after immersion.

It may be suggested that the appearance of the tentorial opening, investigated after death and after fixation, does not accurately reflect that present during life. Such a view cannot be absolutely refuted but it, nevertheless, seems untenable, for examination of the dural tent with its attachment to the base of the skull intact conclusively demonstrates its remarkable strength and rigidity as well as its smooth and regular outlines. However importanto is are the effects of post-mortem change or of fixing fluib 6 on the brain, it seems impossible that these could materially deform the free dura and thus the shape of the tentorial opening, without some distortion being readily identified. This was never found.

\section{Opening of the Skull}

The tentorial opening was approached from below by removing the floor of the posterior fossa in order to expose the brain-stem and cerebellum. A transverse cut through the pons made it possible to shell these structures out in one piece only, leaving behind the most dorsal part of the vermis and of the lateral lobes of the cerebellum. The edge of the tent was next defined and further progressively more rostral cuts made through the brain-stem until this level was reached. In some cases the remainder of the skull was then removed, the hemispheres being kept intact within their dural sheath (apart from the original pre-frontal ablation); in others only the cap was removed and the base of the skull was left with the dura still attached. In either case it was possible, by making appropriate cuts round the dura of the convexity and through the perforating vessels, etc., to lift out the brain in such a way that it could be replaced at will, much as an egg can be slipped into an egg cup.

The tentorium cerebelli with the brain in place was then photographed from below; the tentorium was lifted away and a second photograph was taken of the exposed base of the brain. In this way the exact relation of the dural edge to the adjacent cerebral structures was shown. A scale was included in each photograph and all enlargements were made to the same magnification.

\section{Observations on the Tentorial Opening}

In the following illustrations (Figs. 3 to 8 ) the pictures are the natural size. The right side of the 


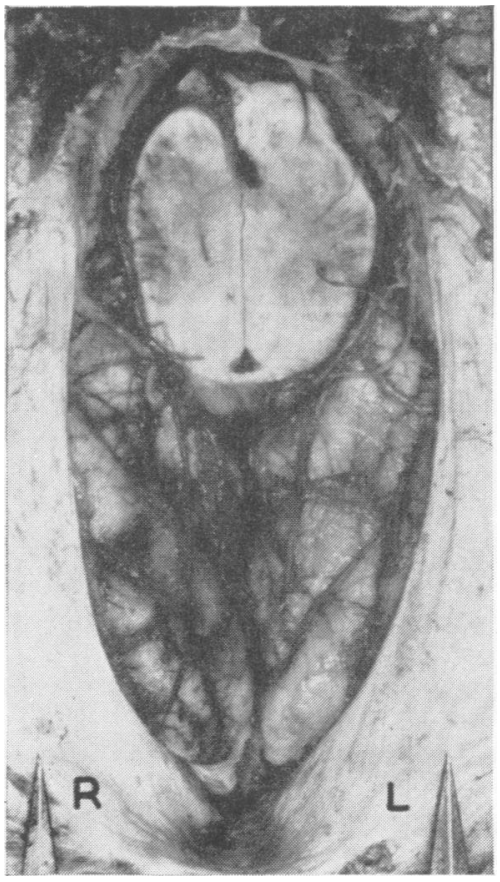

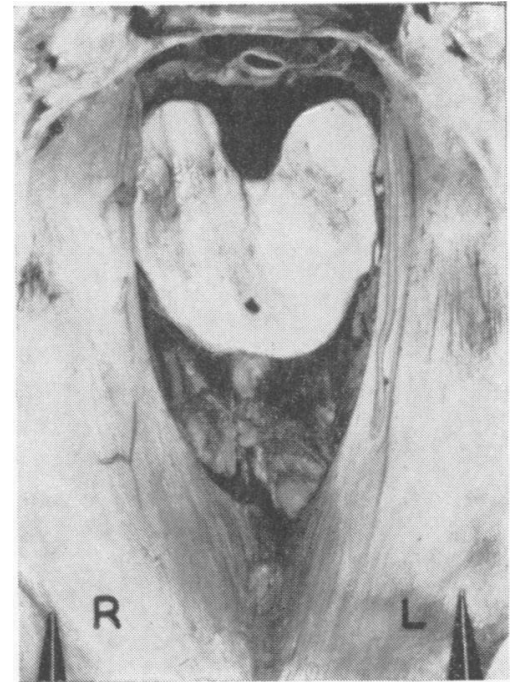

Fig. 4.-Case 9, male, aged 65. $\times 1$.

Fig. 3.-Case 12, female, age 33 , the tentorial opening seen from below with the cerebral hemispheres and upper brain-stem in position. $\times 1$.

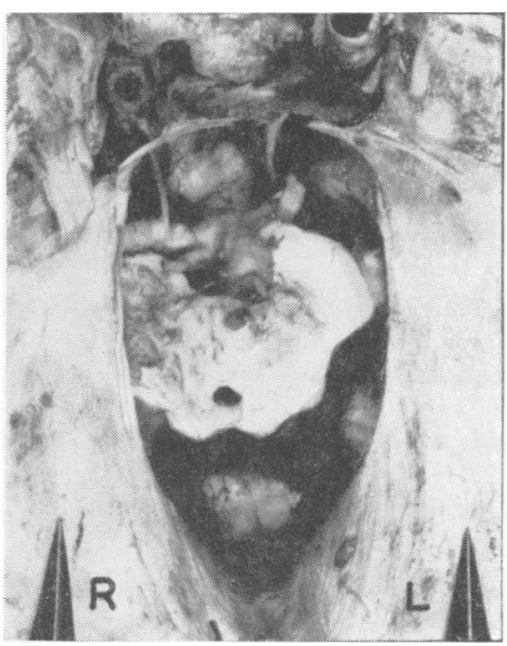

Fig. 6 - Case 5, female, age 51. $\times 1$.

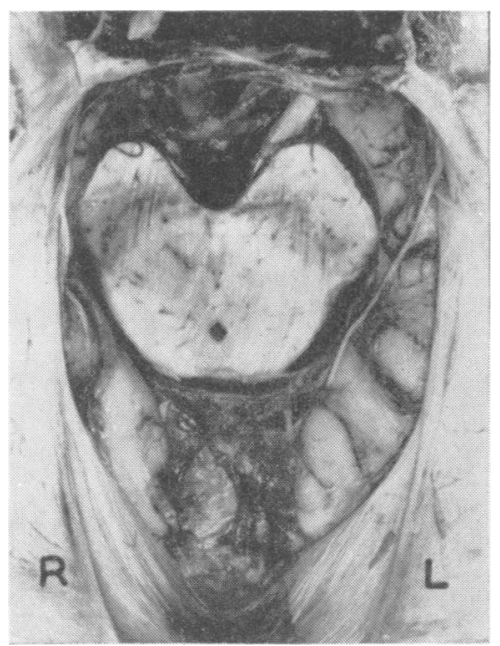

FIG. 7.-Case 1, male, age $53 . \times 1$.

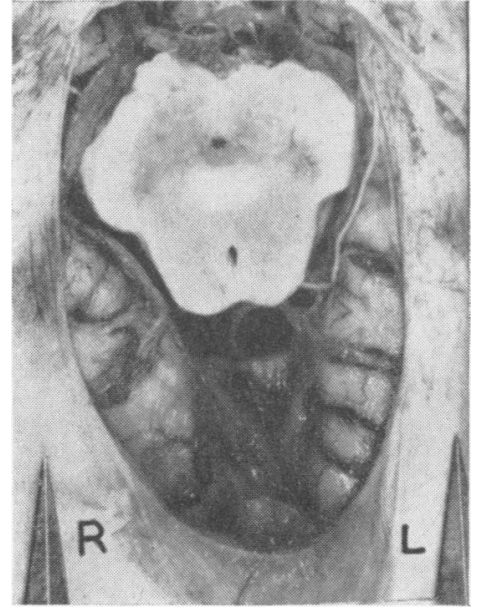

Fig. 5.-Case 6, female, age $65 . \times 1$.

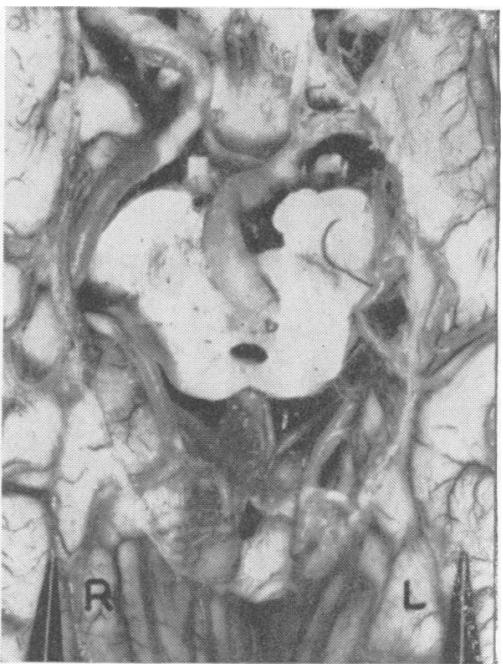

Fig. 8.-Case 7 , male, age 83 , the same view as previously but with the tent removed to show that its limits are still clearly marked out by the cut edge of the leptomeninges. $\times 1$. 


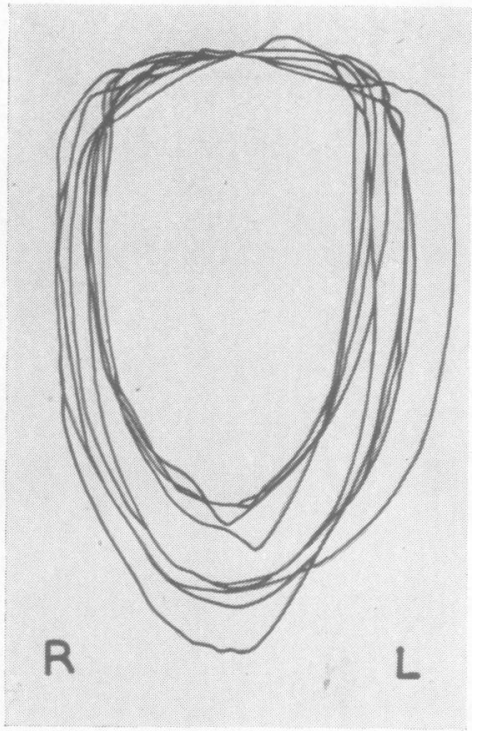

FIG. 9

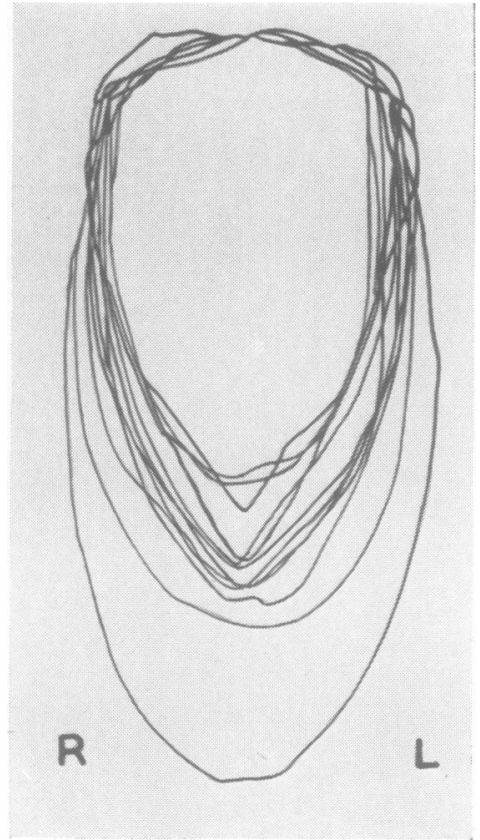

FIGs. 9 and 10.-Composite tracings of the male (Fig. 9) and female (Fig. 10) outlines. $\times 1$. brain is always on the left side of the photograph. Each illustration has the appropriate case number against it and can be identified in the first column of the table.

On comparing the series of photographs, it became obvious that the tent fitted round the brain-stem much more tightly in some cases than in others. At one extreme (Figs. 3 and 5) a major part of both hippocampal gyri would be exposed, while at the other virtually nothing was to be seen (Figs. 4 and 6).
In some cases (Figs. 7 and 8) the two hippocampal gyri were unequally exposed.

The crucial difference did not lie either in the variation of the cross-sectional area of the brainstem or even in the presence of brain swelling; it clearly lay in the size of the tentorial opening.

As the illustrations would suggest, the differences were sufficiently gross for a series to be roughly graded by eye, but since the photographic recording had been done systematically it was possible to

TABLE

CLINICAL DATA AND MEASUREMENTS OF TENTORIAL OPENING

\begin{tabular}{|c|c|c|c|c|c|}
\hline $\begin{array}{l}\text { Case } \\
\text { No. }\end{array}$ & Sex & $\begin{array}{l}\text { Age at } \\
\text { Death }\end{array}$ & Cause of Death & Due to or in a Case of & $\begin{array}{l}\text { Approximate } \\
\text { Size of Tentorial } \\
\text { Opening } \\
\text { (sq. cm.) }\end{array}$ \\
\hline $\begin{array}{r}13 \\
5 \\
11 \\
9 \\
21 \\
16 \\
18 \\
20 \\
14 \\
3 \\
10 \\
19 \\
17 \\
15 \\
8 \\
2 \\
7 \\
6 \\
4 \\
1 \\
12\end{array}$ & $\begin{array}{l}\mathbf{F} \\
\mathbf{F} \\
\mathbf{M} \\
\mathbf{M} \\
\mathbf{F} \\
\mathbf{M} \\
\mathbf{M} \\
\mathbf{F} \\
\mathbf{F} \\
\mathbf{F} \\
\mathbf{M} \\
\mathbf{F} \\
\mathbf{F} \\
\mathbf{F} \\
\mathbf{F} \\
\mathbf{M} \\
\mathbf{M} \\
\mathbf{F} \\
\mathbf{M} \\
\mathbf{M} \\
\mathbf{F}\end{array}$ & $\begin{array}{l}\mathbf{6 9} \\
51 \\
\mathbf{6 5} \\
\mathbf{6 5} \\
\mathbf{7 9} \\
\mathbf{8 2} \\
\mathbf{8 8} \\
\mathbf{8 6} \\
\mathbf{4 0} \\
\mathbf{6 8} \\
81 \\
\mathbf{9 3} \\
\mathbf{7 9} \\
\mathbf{6 9} \\
\mathbf{6 6} \\
\mathbf{7 4} \\
\mathbf{8 3} \\
\mathbf{6 5} \\
\mathbf{7 9} \\
\mathbf{5 3} \\
\mathbf{3 3}\end{array}$ & $\begin{array}{l}\text { Cerebral haemorrhage } \\
\text { Cardiac infarction } \\
\text { Bronchopneumonia } \\
\text { Carcinoma of bladder } \\
\text { Aortic stenosis } \\
\text { Carcinoma of oesophagus } \\
\text { Pulmonary embolus, femoral thrombosis } \\
\text { Bronchopneumonia } \\
\text { Cerebral tumour } \\
\text { Cerebral haemorrhage } \\
\text { Cardiac infarction } \\
\text { Bronchopneumonia } \\
\text { Bronchopneumonia } \\
\text { Myocardial degeneration } \\
\text { Bronchopneumonia } \\
\text { Acute bronchitis } \\
\text { Cardiac infarction } \\
\text { Myocardial degeneration } \\
\text { Aortic stenosis } \\
\text { Wernicke's encephalopathy } \\
\text { Haemorrhagic leuco-encephalitis }\end{array}$ & $\begin{array}{l}\text { Ruptured aneurysm } \\
\text { Arteriosclerotic psychosis } \\
\text { Cryptogenic epilepsy } \\
\text { Paraphrenia } \\
\text { Schizophrenia } \\
\text { Cryptogenic epilepsy } \\
\text { Arteriosclerotic psychosis } \\
\text { Mania } \\
\text { Senile psychosis } \\
\text { Senile psychosis } \\
\text { Alzheimer's disease } \\
\text { Depression } \\
\text { Arteriosclerotic psychosis } \\
\text { Cryptogenic epilepsy } \\
\text { Mania } \\
\text { Pulmonary tuberculosis }\end{array}$ & $\begin{array}{l}10 \\
10 \\
10 \\
10 \\
11 \\
11 \\
11 \\
11 \\
12 \\
12 \\
12 \\
13 \\
14 \\
14 \\
14 \\
15 \\
16 \\
16 \\
17 \\
18 \\
23\end{array}$ \\
\hline
\end{tabular}


demonstrate the range a little more clearly, first by estimating the approximate size of the area in each case, and secondly by building up composite tracings of the individual outlines.

It must be emphasized that both the measurements and the tracings are intended as rough guides and relate only to the present series in which a particular technique was used. They record, not the real size and shape of the opening, but that found when the dorsal curvature of the tent has been flattened out and so foreshortened. In the present context greater accuracy would seem to be unnecessary. It might even be misleading, since the outline of the tent itself, especially along its anterior border, is not always clear cut.

The measurements are tabulated with details of each case and arranged simply in order of the size of the tentorial opening.

For the tracings, the cases were first split into male and female; the magnification is the same as that in the previous illustrations, namely $\times 1$.

Nine males and 12 females were examined, the age at death ranging from 33 to 93 , but with twothirds over 65 .

The size of the tentorial opening in these cases therefore ranged from about 10 to about $23 \mathrm{sq} . \mathrm{cm}$.; that is, the largest was over twice the size of the smallest. The tracings explain themselves.

\section{Discussion}

It is conceivable that these differences might be related to sex or to the atrophy of old age but the distribution of the cases in the table gives little or no support to either suggestion. At the same time, it is difficult to imagine what other factors might be of importance for-short of tearing-the tentorium seems too strong and too well anchored to be stretched once its development is complete.

In other words, the outline of the opening presumably remains virtually constant during adult life and is established during the period of growth. Its variability then from case to case is simply a manifestation of the range of normal development, although the possible influence of pathological conditions occurring in early life should not be ignored.

From the applied point of view, however, the salient fact is that such marked variation occurs at all for the pattern of any herniation must be to some extent affected by the size and shape of the ring through which the brain is being forced.

Although it is not possible to go further than this at present, such an assertion could easily be tested by applying the same technique to an adequate series of cases with raised intracranial pressure. In relation to the problem of herniation in general, it might also be useful to compare diagnostic injection studies, either of the ventricles or of the blood vessels, carried out during life with these repeated after death.

Such an approach, in fact, might well provide fresh information about a number of those conditions in which the brain is thought to have moved decisively within the skull. It was for the study of one of these-the relation of the infero-medial parts of the temporal lobe to epilepsy-that the present technique was originally planned, and is now being used.

\section{Summary}

A post-mortem technique is described for the routine removal of the brain, apart from the prefrontal areas, within the skull.

Using this method, the tentorial opening has been studied in 21 cases and a marked individual variation in its size is described.

The possible implications of this to transtentorial herniation are briefly discussed and other ways in which the technique might be of use are suggested.

I am very grateful to Dr. R. Ström-Olsen for his encouragement in carrying out this work and to Dr. D. C. Caldwell and Dr. W. H. Bennison for their cooperation in the collection of material.

I would particularly like to thank Professor Peter Daniel, Dr. J. B. Brierley, and Dr. Sabina Strich for their active help and advice at all times.

\section{REFERENCES}

Martin, D. (1952). Med. biol. Ill., 2, 260.

Small, J. M., and Woolf, A. L. (1957). J. Neurol. Neurosurg. Psychiat., 20, 293 . 